\title{
Alternative Multidisciplinary Management Options for Locally Advanced Non-Small Cell Lung Cancer During the COVID-19 Global Pandemic
}

Sameera Kumar, $\mathrm{MD}^{1}$; Steven Chmura, MD, $\mathrm{PhD}^{2}$; Clifford Robinson, $\mathrm{MD}^{3}$; Steven H. Lin, MD, PhD ${ }^{4}$; Shirish M. Gadgeel, MD; ;essica Donington, MD; Josephine Feliciano, MD; Thomas E. Stinchcombe, MD; Maria Werner-Wasik, MD; Martin J. Edelman, MD ${ }^{10}$; Drew Moghanaki, MD, MPH ${ }^{11}$

1 Department of Radiation Oncology, Fox chase Cancer Center, Philadelphia, PA

2 Department of Radiation and Cellular Oncology, University of Chicago, Chicago, IL

3 Department of Radiation Oncology, Washington University, St. Louis, MO

4 Department of Radiation Oncology, MD Anderson Cancer Center, Houston, TX

5 Department of Internal Medicine, Division of Hematology and Oncology, University of Michigan, Ann Arbor, MI

6 Department of Surgery, University of Chicago, Chicago, IL

7 Department of Medical Oncology, Johns Hopkins University, Baltimore, MD

8 Department of Medical Oncology, Duke University, Durham, NC

9 Department of Radiation Oncology, Thomas Jefferson University, Philadelphia, PA

10 Department of Hematology and Medical Oncology, Fox Chase Cancer Center, Philadelphia, PA

11 Department of Radiation Oncology, Emory University, Atlanta Veterans Affairs Health Care System, Atlanta, GA

Corresponding author:

Sameera Kumar, MD

sameera.kumar@fccc.edu

Fox Chase Cancer Center

Department of Radiation Oncology

333 Cottman Avenue

Philadelphia, PA 19111

Disclosure of Funding: No funding was received for this work

Conflicts of Interest:

Sameera Kumar, MD has no relevant conflicts of interest. She receives honoraria from AstraZeneca.

Steven Chmura, MD, PhD has no relevant conflicts of interest. He is a consultant for Reflexion Medical. His spouse is employed by Astellas Pharma. He has research support from Bristol Myers Squibb, Varian Medical Systems, and Merck

Clifford Robinson, MD has no relevant conflicts of interest. He is a leader of Radialogica and owns stock in the company. $\mathrm{He}$ is a consultant/advisor for Varian Medical Systems, AstraZeneca, and EMD Serono. His institution receives research funding from Varian Medical Systems, Elekta, and Merck.

Steven H. Lin, MD, PhD has no relevant conflicts of interest. He received grant support from Hitachi Chemical Diagnostics, STCube Pharmaceuticals, Inc., Beyond Spring Pharmaceuticals, and Genetech. He is also on the advisory boards for AstraZeneca, STCube Pharmaceuticals, and Beyond Spring Pharmaceuticals. He is part of the speaker bureau for Varian Medical Systems and AstraZeneca.

Shirish M. Gadgeel, MD has no relevant conflicts of interest. He is on the advisory board for AstraZeneca, Takeda, Genentech/Roche, Novartis, and Daichii-Sanyko. He receives honorarium from Merck. He receives travel support from Merck and Genentech/Roche.

Jessica Donington, MD has no relevant conflicts of interest. She is an advisor for AstraZenenca, Bristol Myers Squibb, and Genetech.

Josephine Feliciano, MD has no relevant conflicts of interest.

Thomas Stinchcombe, MD has no relevant conflicts of interest.

Maria Werner-Wasik, MD has no relevant conflicts of interest.

Martin J. Edelman, MD has no relevant conflicts of interest.

Drew Moghanaki, MD, MPH has no conflicts of interest. He receives honoraria from Varian Medical Systems. 


\section{Abstract:}

Importance: The COVID-19 pandemic is currently accelerating. Patients with locally advanced non-small cell lung cancer (LA-NSCLC) may require treatment in locations where resources are limited and the prevalence of infection is high. Patients with LA-NSCLC frequently present with comorbidities that increase the risk for severe morbidity and mortality from COVID-19. These risks may be further increased by treatments for LA-NSCLC.

Observation: We present expert thoracic oncology multidisciplinary (radiation oncology, medical oncology, surgical oncology) consensus of alternative strategies for the treatment of LA-NSCLC during a pandemic. The overarching goals of these approaches are to reduce the number of visits to a healthcare facility, reduce the risk of SARS-CoV-2 exposure, and attenuate the immunocompromising effects of lung cancer therapies. Patients with resectable disease can be treated with definitive non-operative management if surgical resources are limited or the risks of perioperative care are high. Non-operative options include chemotherapy, chemoimmunotherapy, and radiation therapy with sequential schedules. The order of treatments may be based on patient factors and clinical resources. Whenever radiation therapy is delivered without concurrent chemotherapy, hypofractionated schedules are appropriate. For patients who are confirmed to have COVID19 , usually cancer therapies may be withheld until symptoms have resolved with negative viral test results.

Conclusions and Relevance: The risk of severe treatment-related morbidity and mortality is significantly elevated for patients undergoing treatment for LA-NSCLC during the COVID-19 pandemic. Adapting alternative treatment strategies as quickly as possible may save lives and should be implemented through communication with the multidisciplinary cancer team.

Keywords: Non-small cell lung cancer, locally advanced, COVID, SARS-CoV-2

\section{Introduction:}

The novel betacoronavirus SARS-CoV-2 that results in coronavirus disease 2019 (COVID-19) has led to a global pandemic. As of this writing, over 1.3 million cases have been diagnosed in the world and the incidence continues to rise. ${ }^{1}$ As a result, healthcare facilities in many areas are becoming or have already become resource-constrained. Locally advanced non-small cell lung cancer (LA-NSCLC) continues to be diagnosed, many patients are symptomatic at the time of diagnosis, and patients may suffer from progression of their disease if initiation of treatment is delayed. Patients must be made aware that LA-NSCLC is a life-threatening disease that requires treatment, while both the workup and treatment may increase their risk of exposure to COVID-19. Cancer therapies can lead to prolonged immunocompromised states that may affect the probability of severe infection-related morbidities and mortality. Their treatments require multiple visits to healthcare facilities that put them at high risk for COVID-19. As such, an urgent need has emerged to consider alternative management options that may save lives.

Due to the novel nature of the SARS-CoV-2 virus, there are limited data regarding the long-term benefits or costs of modifications to the standard of care which are made due to risks of infection or constrained resources. However, LA-NSCLC patients often cannot wait for treatment to start at a time that data are available, risks of infections have completely passed, or resources are plentiful. Clinical judgment will be necessary to decide whether a modification in the standard of care is warranted.

Currently, several organizations including the American Society of Radiation Oncology (ASTRO) and American Society of Clinical Oncology (ASCO) have published recommendations for cancer care 
during the COVID-19 pandemic. ${ }^{2,3}$ A more radiotherapy-focused addition was a consensus statement that was recently published on April 1, 2020 by the European Society of Radiation Oncology (ESTRO) and ASTRO that covered various clinical scenarios for lung cancer radiotherapy. ${ }^{4}$ The ESTRO-ASTRO consensus was developed though a modified Delphi process with 32 experts in radiation oncology. Adding to this consensus statement, the report submitted herein presents a focused set of recommendations for managing LA-NSCLC that were developed by a multidisciplinary panel of 11 experts in radiation, medical, and surgical oncology using a series of virtual meetings and discussions. A summary of these recommendations can be found in Table 1.

\section{Why Consider Alternative Treatment Strategies?}

Patients with LA-NSCLC are generally older and frequently present with high-risk comorbidities that may limit their ability to survive a COVID-19 infection. The evidence for factors that contribute to COVID-19 related mortality continues to emerge, and may include baseline co-morbidities that are common in patients with lung cancer which includes poor pulmonary reserve due to chronic lung disease, cardiac disease, diabetes, and other comorbidities. ${ }^{5-7}$ Patients may also have symptoms related to lung cancer that may mask evidence of COVID-19 and delay detection.

Unfortunately, treatments for LA-NSCLC require numerous visits and exposures to healthcare facilities that increase patient and healthcare provider risks of acquiring COVID-19. Surgical care may entail multiple cycles of induction chemotherapy followed by perioperative care that requires hospitalization and carries high risks for patients and healthcare staff. Non-operative treatments generally require 6 weeks of daily chemoradiation followed by 12 months of durvalumab delivered every 2 weeks. Whether treated with surgery, radiation therapy, or systemic therapy, each of these treatments can be immunosuppressive and impair patients' ability to clear the virus. Published data from China and Italy have shown that the mortality risk of COVID-19 in patients with cancer is high, a finding that may be the result of malignancy, treatment effects, or likely both. ${ }^{8-11}$ Those who had undergone recent anti-tumor therapies including surgery, chemotherapy, and radiation therapy were particularly at risk. While these recent reports were retrospective, evaluated small cohorts, and had methodological limitations, they bring attention to the potential consequences of viral related pneumonia, acute respiratory distress, and sepsis that can occur as a result of COVID-19 in patients undergoing treatment for LA-NSCLC.

Meanwhile, alternative treatment strategies for patients with LA-NSCLC, as discussed below, offer opportunities to mitigate risks of harm by reducing patient exposures to healthcare facilities and the immunocompromising effects of potentially toxic treatments. The risks of making these changes likely have minimal impacts on overall survival and should be weighed against the risk of death and disability from developing COVID-19.

\section{Pathological Diagnosis and Nodal Staging During a Pandemic}

All diagnostic procedures increase the risk for exposure to COVID-19. At this time, a pathological diagnosis of malignancy may be sufficient to initiate treatment for LA-NSCLC rather than rescheduling 
a repeat biopsy for further subtyping, unless specific oncogenic mutation would affect management. The priority to stage the mediastinum with bronchoscopy and mediastinoscopy may need to be revisited during a highly infectious pandemic given these procedures may increase the risk of contracting COVID-19 for patients and staff due to their aerosolized nature. ${ }^{12,13}$ Availability of invasive staging procedures may ultimately be limited since pulmonologists and surgeons are increasingly needed for critical care services, operating room time may be unavailable, and therefore initiation of treatment should not be delayed if these procedures cannot be performed in a timely manner. Nodal staging by imaging has relatively high accuracy and can be an appropriate substitute at this time. ${ }^{14-16}$ 18F-FDG-PET/CT scans have high sensitivity for occult regional and distant disease and can also help define treatment targets for radiation therapy planning. ${ }^{17}$ Acquisition of PET/CT images requires considerably more time (hours) in radiology departments than contrast-enhanced CT (minutes) and the limitations of each should be considered. In the event that PET/CT staging is not available, staging can be performed by $\mathrm{CT}$ alone by categorizing any mediastinal lymph node $>1 \mathrm{~cm}$ on shortaxis diameter as positive and therefore should be targeted with radiation therapy. ${ }^{18,19}$ However, patients who are staged without an 18F-FDG-PET/CT should be informed that CT alone is not as sensitive or specific. Ultimately, all LA-NSCLC cases should be carefully reviewed with a radiologist for input on the malignant appearance of lymph nodes and opinions on defining radiotherapy treatment targets if non-surgical managements are pursued. In the absence of pathological mediastinal staging, radiation oncologists should consider targeting all hypermetabolic (or enlarged on CT scan) lymph nodes with definitive doses.

\section{Surgical Management}

Surgery plays a key role in the treatment of patients with single-station and low volume Stage IIIA NSCLC. Surgical decisions are typically guided by careful patient-centered risk-benefit assessments, but currently healthcare resource allocation and risk to the treatment team must be included in that challenging decision. The Centers for Disease Control, American College of Surgeons, and numerous government agencies have recommended cancellation of elective surgery during the global pandemic and creation of a tiered system for prioritization of other surgical procedures. ${ }^{20-22}$ Lung cancer resections fall into the scope of Medically Necessary Time Sensitive (MeNTS) procedures. ${ }^{23}$ For patients with LA-NSCLC who have completed induction therapy, the time sensitivity is particularly crucial, as the window for meaningful and safe surgical intervention typically spans over a 4 to 12 week period. Unfortunately, exposure risks and resource utilization for lung resections are high; they require general anesthesia, manipulation of the aero-digestive tract, and a hospital stay. The decision of whether to proceed with surgery is highly dependent on the current phase of the pandemic at the treating institution. Those in the early phase, where there are adequate healthcare resources, (operating rooms, ventilators, hospital beds, surgeons, and anesthesiologists) may choose to proceed while those in the later stages will have little choice but to defer planned resections. While there is an argument that a brief operative intervention for stage I disease might only require a 1-2 night hospital stay and produce less exposure risk and resource utilization than radiation therapy, the same does not apply for LA-NSCLC where the potential post-induction hilar and mediastinal fibrosis increases the risk for an open procedure (if delayed beyond the "window of opportunity"), prolonged hospital stay, and perioperative complications. Early reports of severe COVID-related complications and high post-operative mortality in asymptomatic infected patients undergoing elective operations are 
sobering, and resources in most communities do not allow for pre-operative screening of asymptomatic patients. ${ }^{24}$ Some centers recommend a CT scan immediately prior to surgery to look for early bilateral pulmonary infiltrates, but uniform recommendations do not currently exist. Unfortunately, the accessibility of surgery for lung cancer patients will become more limited over the coming weeks and we need to consider alternative treatment strategies. Most of these patients who would normally have surgical management of their locally advanced lung cancer may instead receive non-surgical management due to constrained resources and risks associated with perioperative management. ${ }^{25,26}$ Therefore, non-operative management of surgically resectable LA-NSCLC patients should be considered.

\section{Non-Operative Management}

There are two key dilemmas for the non-operative management of LA-NSCLC. The first relates to the general approach of treatment with 6 weeks of concurrent chemoradiation therapy followed by consolidation durvalumab given every 2 weeks for an additional 12 consecutive months. The frequency and duration of these treatments subject patients, healthcare providers, and other potentially immunocompromised cancer patients to high risks of acquiring a SARS-CoV-2 infection. The second dilemma relates to the immunocompromising effects of chemotherapy and radiation therapy which are increased whenever given concurrently 5 days a week for 6 consecutive weeks. Each of these dilemmas creates a high-risk environment for an intercurrent COVID-19 that will generally lead to a treatment interruption which is known to increase mortality. ${ }^{27}$ Strategies to mitigate these risks are described below.

The use of sequential radiation and chemotherapy offers an opportunity to reduce the combined immunosuppressive effects of concurrent chemoradiotherapy and deliver a treatment that is better tolerated. This recommendation is based on randomized data that demonstrates higher rates of grade 3 or higher leukopenia with concurrent schedules for LA-NSCLC and the finding that lymphopenia can predict disease severity in COVID-19 patients. ${ }^{28-30}$ Such a modification requires careful coordination between medical oncologists and radiation oncologists if this approach represents an unfamiliar paradigm and schedule. Sequential therapies minimize the incidence of treatment-related pneumonitis which may enable providers to differentiate potential signs of viral illness from the side effects of therapy. While the overall survival benefits with concurrent chemoradiation versus sequential therapy were established with randomized phase III data, the absolute benefit is modest relative to toxicity and it's unclear how relevant this is for contemporary patients with improved staging (PET/CT) and use of consolidation immunotherapy. ${ }^{29,31}$

Whenever considering sequential therapy, the order of which therapy to initiate first should be based on clinical and situational factors such as patient symptoms, rate of progression of disease, overall disease burden, and available resources, amongst other factors. Upfront radiation therapy should be considered whenever tumors are either causing or likely to cause symptoms due to the presence of hilar disease, bronchial/vascular compression, atelectasis, pulmonary symptoms, and pneumonia. ${ }^{32}$ Patients without these features may be best treated with upfront systemic therapy followed by radiotherapy alone or chemoradiotherapy. Upfront systemic therapy decreases patient exposure to 
one visit every several weeks and postpones initiation of daily radiation therapy treatments.

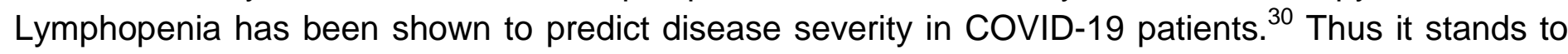
reason that limiting exposures while patients are experiencing chemotherapy-induced lymphopenia may be beneficial.

The use of durvalumab should also be considered in these patients. This is a recommendation that is based on the phase III PACIFIC trial where $25.3 \%$ of patients received induction chemotherapy followed by chemoradiation therapy before receiving durvalumab. ${ }^{33}$ Patients on the PACIFIC trial received concurrent chemoradiation, and the use of sequential chemotherapy and radiation followed by durvalumab is currently being investigated on the PACIFIC 6 trial. $^{34}$ Following radiotherapy and chemotherapy, consideration can be made to deliver durvalumab at a dose of 1500 mg every 4 weeks (instead of every 2 weeks) since this is a schedule that has been used in other trials. ${ }^{35-37}$ Per the PACIFIC trial, administration of durvalumab can be given up to 6 weeks after chemoradiation. On an unplanned subgroup analysis those patients that were able to initiate therapy with durvalumab within 14 days had better outcomes, but these data are confounded by multiple variables. ${ }^{33}$

Patients treated with sequential therapy have an opportunity to be treated with a hypofractionated schedule with treatment courses as short as 3 weeks. Multiple studies have demonstrated such an approach to be safe and effective. ${ }^{38-40}$ Shorter courses have been associated with decreased immunosuppression in other cancers such as leukemia and pancreatic cancer. ${ }^{41-43}$ This may offer advantages for LA-NSCLC, although minimizing the number of visits may provide the most risk reduction. Approaches employing 15 and 20 fraction schedules preceded the current pandemic and have already been demonstrated to be safe and effective. Short courses can be delivered with either induction or adjuvant chemotherapy or chemoimmunotherapy. Standard chemotherapy schedules can be referenced in evidence-based guidelines such as those found in the National Cancer Network Guidelines with consideration of schedules that minimize the frequency of visits to a healthcare institution. ${ }^{44}$ Table 2 summarizes commonly used hypofractionated schedules for locally advanced lung cancer. The use of intensity modulated radiation therapy (IMRT) techniques is encouraged for hypofractionation as it can minimize the volume of normal tissues exposed to the prescription dose. Whenever normal organ dose constraints cannot be met during hypofractionated radiotherapy treatment planning, radiation oncologists should consider delivering the full prescription dose to the gross tumor volume (GTV) and a planning treatment volume (PTV) margin while reducing the dose prescribed to the clinical treatment volume (CTV) and a PTV margin. This can be often achieved with IMRT using a simultaneous integrated boost technique. ${ }^{45}$

Regarding the definition of radiation treatment volumes, we urge our colleagues to avoid elective lymph node irradiation which is an outdated approach to the radiotherapeutic management of LANSCLC. ${ }^{46-48}$ The extension of target volumes to include even one nodal stage superiorly and/or inferiorly increases the risk of treatment-related immunosuppression and pneumonitis that may mask early symptoms of COVID-19. If contouring nodal stations with CT alone, radiation oncologists should consider including any lymph nodes $>1 \mathrm{~cm}$ in the short-axis (not greatest dimension). Also, daily image guidance using conebeam CT may help to assess development of infiltrates in asymptomatic patients. 
If there is a preference to deliver concurrent chemoradiation, then induction chemotherapy may be considered to delay the time to when patients need to come in for daily chemoradiotherapy treatments. Results from randomized phase II and III trials support such an approach after having compared chemoradiotherapy with or without induction chemotherapy and shown similar survival rates. ${ }^{4-51}$ While the use of induction chemotherapy prolongs the total length of treatment, it offers an opportunity at this time to delay initiation of chemoradiotherapy which requires daily visits at facilities that may soon be resource-constrained.

\section{COVID-19 Infected Patients}

Once a patient with LA-NSCLC develops COVID-19, specific patient and treatment factors should be considered before the decision is made to hold or continue therapy. These factors include patient symptoms, status and growth rate of NSCLC, and available resources within the healthcare facility, among other factors. If a patient has a significant obstruction, hemoptysis, or other symptoms that may be alleviated by oncologic treatment, treatment should be considered. This may be radiotherapy alone to decrease the chance of chemotherapy induced lymphopenia, which may adversely affect outcomes from a COVID-19 infection. If patients with COVID-19 infections are to be treated, strategies such as strict personal protective equipment use for patients and staff, physical separation of infected and uninfected patients, and frequent and robust sanitation of equipment should be implemented. For patients receiving radiotherapy, if separate waiting rooms, changing facilities, and different machines can be used, this may be ideal. Treating patients with COVID-19 at the end of the day and thoroughly cleaning all facilities may also limit the spread of the virus. These strategies have been described in depth in reports from China, Italy and the United States of America. ${ }^{52-55}$

Meanwhile, a patient who tests positive for COVID-19 and is asymptomatic, may still be considered physiologically unfit to tolerate any further lung cancer therapies as many patients develop worsening symptoms in the second week of infection. ${ }^{56}$ Early studies have shown that COVID-19 can lead to acute respiratory distress syndrome with pathological changes such as destruction of the alveoli and cellular fibromyxoid exudates. ${ }^{57,58}$ These pathologic changes may lead to permanent destruction of lung tissue. This also leads to an increase in inflammatory biomarkers which have been correlated to severity in COVID-19 patients. ${ }^{59}$ Similarly, serum inflammatory cytokines have been shown to be predictive of both thoracic toxicity and survival following thoracic radiotherapy. ${ }^{60-64}$ While these data raise concerns, we are not entirely sure how they can manifest in patients with COVID-19 as the data on this pandemic are still emerging and the degree of morbidity seen has been variable. The effects of the virus and lung cancer therapies may simultaneously damage pulmonary tissue and increase the chance of pneumonitis. This may be further worsened if patients' immune systems are compromised and patients are unable to efficiently clear the virus. It is recognized that treatment delays or interruptions for lung cancer may lead to worse oncologic outcomes. ${ }^{27}$

For patients with COVID-19, the clinical focus should include aggressive and supportive care with consultation of infectious disease and critical care specialists with possible enrollment into clinical trials directed at COVID-19. These efforts can help restart cancer therapy as soon as possible. It is 
important to emphasize that the challenges of managing patients with COVID-19 are best avoided by the strategies recommended above in order to prevent an infection in the first place.

\section{Preserving Effective Communication and a Multidisciplinary Approach}

Communication must be frequent with all healthcare providers who may be unfamiliar with any of the recommended alternative treatment approaches. Clinicians should have heightened awareness about the importance of careful and thorough documentation, especially if cross-coverage is needed in the event of an unexpected event. Multi-disciplinary tumor board reviews should continue to be held for all patients, even remotely if needed at this time. This ensures thoughtful reviews for each and every case with input from radiologists as mentioned above. It also affords an opportunity for medical oncologists to discuss the risks and benefits of different systematic treatment approaches in the context of COVID-19 risk and allows radiation oncologists to describe the rationale for alternative treatment schedules. Clinicians also need to have careful and informative conversations with each patient regarding any deviations from the standard of care. Topics such as risks, benefits, and reasoning for these deviations must be explained so that they can have a proper understanding of the trajectory of their care. The wishes of the patient must also be factored into how each patient is managed. Patients should also be counseled to self- isolate during treatment to reduce the risk of infection to themselves and other cancer patients.

\section{Final Considerations Regarding Lung Cancer Stigma and Nihilism}

Recent reports in the media indicate that healthcare systems are taking measures during the global pandemic to ration resources that may limit access to care for patients living with lung cancer. This includes restricting access to a ventilator if they develop respiratory distress for any reason whether related to COVID-19 or not. Healthcare administrators and colleagues taking care of these acutely ill patients on the front line may be largely unaware of recent advances in lung cancer care and the opportunity for long-term survival in all lung cancer patients regardless of stage. Efforts to protect against nihilism may be therefore needed more than ever before. Educating our colleagues and citing evidence may be helpful, such as pointing to recent results from the PACIFIC trial demonstrating 3 year overall survival of $66 \%$ in patients with LA-NSCLC in patients treated with chemoradiotherapy and consolidation durvalumab. ${ }^{65}$

\section{Conclusions}

Patients with newly diagnosed LA-NSCLC are a vulnerable population during the COVID-19 global pandemic. Standard of care strategies with surgery, radiation therapy, and systemic therapies can take a long time to deliver and expose patients to multiple visits to healthcare facilities. Patients who are confirmed to have COVID-19 should be considered to have their cancer therapies withheld until they are fully recovered. However, the initiation of treatment for patients without an infection should not be delayed. The alternative treatment strategies that are presented in this report can reduce risk and should be considered for each patient while the global pandemic persists. Some surgical, radiation, and medical oncology practices may be currently operating in geographic locations that have not yet been hit by this pandemic. However, with this pandemic having reached across the 
globe, the authors urge all oncologists to consider these measures to optimize patient outcomes until this current crisis is over.

Table 1: A summary of the expert recommendations of modifications to the standard of care during times of increased risk of infection or constrained resources.

\begin{tabular}{|c|c|}
\hline Topic & Recommendation \\
\hline Hilar and mediastinal staging & $\begin{array}{l}\text { Consider staging the mediastinum with } 18 \mathrm{~F}-\mathrm{FDG}-\mathrm{PET} / \mathrm{CT} \text { and avoid invasive } \\
\text { mediastinal staging with endobronchial ultrasound and/or mediastinoscopy } \\
\text { If } 18 \mathrm{~F}-\mathrm{FDG}-\mathrm{PET} / \mathrm{CT} \text { is not available, consider staging the hilum and mediastinum } \\
\text { with a CT with contrast }\end{array}$ \\
\hline Surgical management & $\begin{array}{l}\text { The decision of whether to proceed with surgery is highly dependent on the current } \\
\text { phase of the pandemic at the treating institution. } \\
\text { Avoid surgery in SARS-CoV-2 positive patients, even if asymptomatic. Pre- } \\
\text { operative CT of the chest may help detect asymptomatic carriers of SARS-CoV-2 } \\
\text { prior to surgery } \\
\text { Non-operative management of LA-NSCLC may be utilized }\end{array}$ \\
\hline Chemoradiation & $\begin{array}{l}\text { Consider sequential chemoradiation } \\
\text { If using sequential therapy, the decision of whether to pursue systemic therapy or } \\
\text { radiation first will depend on clinical factors and available resources } \\
\text { Consider induction systemic therapy } \\
\text { Consider durvalumab after concurrent or sequential chemoradiation } \\
\text { If utilizing durvalumab after chemoradiation, consider q4 week dosing or delaying } \\
\text { initiation of durvalumab (within } 42 \text { days) }\end{array}$ \\
\hline Radiation techniques & $\begin{array}{l}\text { Utilize IMRT with a hypofractionated schedule } \\
\text { Elective nodal coverage is not needed and may increase toxicity } \\
\text { In the absence of pathological hilar or mediastinal staging treat all hypermetabolic } \\
\text { lymph nodes as if they are positive for disease. If CT with contrast was used alone, } \\
\text { consider treatment of all lymph nodes }>1 \mathrm{~cm} \text { in short axis }\end{array}$ \\
\hline $\begin{array}{l}\text { Treating } \\
\text { patients }\end{array}$ SARS-CoV-2 infected & $\begin{array}{l}\text { The decision to treat these patients depends on patient and disease factors and } \\
\text { availability of resources. } \\
\text { Consider treatment in patients who have tumor obstructions, hemoptysis or are } \\
\text { symptomatic from their LA-NSCLC, especially if there are not better alternatives } \\
\text { Consider holding treatment in patients who are symptomatic from the infection and } \\
\text { whose malignancy would most likely not progress during the delay/interruption } \\
\text { Focus of care should shift to supportive/anti-infectious methods, so that the patient } \\
\text { can resume optimal oncologic therapy as soon as possible. In these patients } \\
\text { oncologic care can be resumed when symptoms have resolved and the patient } \\
\text { tests negative }\end{array}$ \\
\hline Communication & $\begin{array}{l}\text { Robust communication is needed with all members of the patient's care team } \\
\text { Deviations from the standard of care should be discussed in multidisciplinary tumor } \\
\text { board }\end{array}$ \\
\hline
\end{tabular}


The patient must be made aware of the risks and benefits of treatment, including deviations in the standard of care

Avoiding nihilism We must advocate for our patients as many have good outcomes

Table 2: Commonly used hypofractionated radiation therapy schedules for LA-NSCLC

\begin{tabular}{|l|l|l|l|l|}
\hline Total Dose & $\begin{array}{l}\text { Number } \\
\text { Fractions }\end{array}$ & Dose per Fraction & $\begin{array}{l}\text { Biologically } \\
\text { effective dose }(\alpha / \beta \\
\text { ratio }=10)\end{array}$ & References \\
\hline $60 \mathrm{~Gy}$ & 15 & $4 \mathrm{~Gy}$ & $84 \mathrm{~Gy}$ & $45,66-69$ \\
\hline $60 \mathrm{~Gy}$ & 20 & $3 \mathrm{~Gy}$ & $78 \mathrm{~Gy}$ & 70,71 \\
\hline $55 \mathrm{~Gy}$ & 20 & $2.75 \mathrm{~Gy}$ & $70 \mathrm{~Gy}$ & $72-74$ \\
\hline
\end{tabular}

\section{References:}

1. World Health Organization. Coronavirus disease 2019 (COVID-19) situation report-78. Geneva, Switzerland: World Health Organization; 2020.v. https://www.who.int/docs/defaultsource/coronaviruse/situation-reports/20200407-sitrep-78-covid-19.pdf?sfvrsn=bc43e1b_2. Accessed April 8, 2020.

2. FAQs - COVID-19 Resources - American Society for Radiation Oncology (ASTRO) - American Society for Radiation Oncology (ASTRO). ASTRO. https://www.astro.org/Daily-Practice/COVID-19Recommendations-and-Information/COVID-19-FAQs. Accessed April 8, 2020.

3. ASCO Coronavirus Resources. ASCO. https://www.asco.org/asco-coronavirus-information. Published March 6, 2020. Accessed April 8, 2020.

4. Guckenberger M, Belka C, Bezjak A, et al. Practice recommendations for lung cancer radiotherapy during the COVID-19 pandemic: An ESTRO-ASTRO consensus statement. Radiotherapy and Oncology. April 2020. doi:10.1016/j.radonc.2020.04.001

5. Bhatraju PK, Ghassemieh BJ, Nichols M, et al. Covid-19 in Critically III Patients in the Seattle Region Case Series. New England Journal of Medicine. 2020;0(0):null. doi:10.1056/NEJMoa2004500

6. CDCMMWR. Preliminary Estimates of the Prevalence of Selected Underlying Health Conditions Among Patients with Coronavirus Disease 2019 - United States, February 12-March 28, 2020. MMWR Morb Mortal Wkly Rep. 2020;69. doi:10.15585/mmwr.mm6913e2

7. Report sulle caratteristiche dei pazienti deceduti positivi a COVID-19 in Italia II presente report è basato sui dati aggiornati al 17 Marzo 2020. https://www.epicentro.iss.it/coronavirus/bollettino/Report-COVID2019_17_marzo-v2.pdf. Accessed April 6, 2020.

8. Onder G, Rezza G, Brusaferro S. Case-Fatality Rate and Characteristics of Patients Dying in Relation to COVID-19 in Italy. JAMA. March 2020. doi:10.1001/jama.2020.4683

9. Zhang L, Zhu F, Xie L, et al. Clinical characteristics of COVID-19-infected cancer patients: A retrospective case study in three hospitals within Wuhan, China. Annals of Oncology. March 2020. doi:10.1016/j.annonc.2020.03.296

10. Yu J, Ouyang W, Chua MLK, Xie C. SARS-CoV-2 Transmission in Patients With Cancer at a Tertiary Care Hospital in Wuhan, China. JAMA Oncol. March 2020. doi:10.1001/jamaoncol.2020.0980 
11. Liang W, Guan W, Chen R, et al. Cancer patients in SARS-CoV-2 infection: a nationwide analysis in China. The Lancet Oncology. 2020;21(3):335-337. doi:10.1016/S1470-2045(20)30096-6

12. Wahidi MM, Lamb C, Murgu S, et al. American Association for Bronchology and Interventional Pulmonology (AABIP) Statement on the Use of Bronchoscopy and Respiratory Specimen Collection in Patients with Suspected or Confirmed COVID-19 Infection: Journal of Bronchology \& Interventional Pulmonology. March 2020:1. doi:10.1097/LBR.0000000000000681

13. CDC. Interim U.S. Guidance for Risk Assessment and Public Health Management of Healthcare Personnel with Potential Exposure in a Healthcare Setting to Patients with Coronavirus Disease (COVID19). Centers for Disease Control and Prevention. https://www.cdc.gov/coronavirus/2019ncov/hcp/guidance-risk-assesment-hcp.html. Published February 11, 2020. Accessed April 6, 2020.

14. Gupta NC, Tamim WJ, Graeber GG, Bishop HA, Hobbs GR. Mediastinal Lymph Node Sampling Following Positron Emission Tomography With Fluorodeoxyglucose Imaging in Lung Cancer Staging. Chest. 2001;120(2):521-527. doi:10.1378/chest.120.2.521

15. Silvestri GA, Gonzalez AV, Jantz MA, et al. Methods for staging non-small cell lung cancer: Diagnosis and management of lung cancer, 3rd ed: American College of Chest Physicians evidence-based clinical practice guidelines. Chest. 2013;143(5 Suppl):e211S-e250S. doi:10.1378/chest.12-2355

16. Purandare NC, Rangarajan V. Imaging of lung cancer: Implications on staging and management. Indian J Radiol Imaging. 2015;25(2):109-120. doi:10.4103/0971-3026.155831

17. Speirs CK, Grigsby PW, Huang J, et al. PET-Based Radiation Therapy Planning. PET Clinics. 2015;10(1):27-44. doi:10.1016/j.cpet.2014.09.003

18. Erasmus JJ, Sabloff BS. CT, Positron Emission Tomography, and MRI in Staging Lung Cancer. Clinics in Chest Medicine. 2008;29(1):39-57. doi:10.1016/j.ccm.2007.11.004

19. Loutfi S, Khankan A, Ghanim SA. Guidelines for multimodality radiological staging of lung cancer. Journal of Infection and Public Health. 2012;5:S14-S21. doi:10.1016/j.jiph.2012.09.009

20. COVID-19 Guidelines for Triage of Cancer Surgery Patients. American College of Surgeons. https://www.facs.org/covid-19/clinical-guidance/elective-case/cancer-surgery. Accessed April 6, 2020.

21. COVID-19: Guidance for Triage of Non-Emergent Surgical Procedures. American College of Surgeons. https://www.facs.org/covid-19/clinical-guidance/triage. Accessed April 6, 2020.

22. CDC. Interim Guidance for Healthcare Facilities: Preparing for Community Transmission of COVID-19 in the United States. Centers for Disease Control and Prevention. https://www.cdc.gov/coronavirus/2019ncov/hcp/guidance-hcf.html. Published February 11, 2020. Accessed April 6, 2020.

23. Prachand V, Milner R, Angelos P, Posner M, Fung J, Agarwal N, Jeevanandam V, Matthews J. MedicallyNecessary, Time-Sensitive Procedures: A Scoring System to Ethically and Efficiently Manage Resource Scarcity and Provider Risk during the COVID-19 Pandemic. J Amer Coll Surg.

24. Aminian A, Safari S, Razeghian-Jahromi A, Ghorbani M, Delaney CP. COVID-19 Outbreak and Surgical Practice: Unexpected Fatality in Perioperative Period. Ann Surg. March 2020. doi:10.1097/SLA.0000000000003925

25. Brindle M, Gawande A. Managing COVID-19 in Surgical Systems: Annals of Surgery. March 2020:1. doi:10.1097/SLA.0000000000003923 
26. Murthy S, Gomersall CD, Fowler RA. Care for Critically III Patients With COVID-19. JAMA. March 2020. doi:10.1001/jama.2020.3633

27. Nogueira LM, Sahar L, Efstathiou JA, Jemal A, Yabroff KR. Association Between Declared Hurricane Disasters and Survival of Patients With Lung Cancer Undergoing Radiation Treatment. JAMA. 2019;322(3):269-271. doi:10.1001/jama.2019.7657

28. Zatloukal $\mathrm{P}$, Petruzelka $\mathrm{L}$, Zemanova $\mathrm{M}$, et al. Concurrent versus sequential chemoradiotherapy with cisplatin and vinorelbine in locally advanced non-small cell lung cancer: a randomized study. Lung Cancer. 2004;46(1):87-98. doi:10.1016/j.lungcan.2004.03.004

29. Curran WJ, Paulus R, Langer CJ, et al. Sequential vs. concurrent chemoradiation for stage III non-small cell lung cancer: randomized phase III trial RTOG 9410. J Natl Cancer Inst. 2011;103(19):1452-1460. doi:10.1093/jnci/djr325

30. Tan L, Wang Q, Zhang D, et al. Lymphopenia predicts disease severity of COVID-19: a descriptive and predictive study. Signal Transduction and Targeted Therapy. 2020;5(1):1-3. doi:10.1038/s41392-0200148-4

31. Aupérin A, Le Péchoux C, Rolland E, et al. Meta-analysis of concomitant versus sequential radiochemotherapy in locally advanced non-small-cell lung cancer. J Clin Oncol. 2010;28(13):2181-2190. doi:10.1200/JCO.2009.26.2543

32. Higginson DS, Chen RC, Morris DE, et al. Predicting the need for palliative thoracic radiation after firstline chemotherapy for advanced nonsmall cell lung carcinoma. Cancer. 2012;118(10):2744-2751. doi:10.1002/cncr.26495

33. Antonia SJ, Villegas A, Daniel D, et al. Overall Survival with Durvalumab after Chemoradiotherapy in Stage III NSCLC. New England Journal of Medicine. September 2018. doi:10.1056/NEJMoa1809697

34. A Study to Determine Safety of Durvalumab After Sequential Chemo Radiation in Patients With Unresectable Stage III Non-Small Cell Lung Cancer - Full Text View - ClinicalTrials.gov. https://clinicaltrials.gov/ct2/show/NCT03693300. Accessed April 6, 2020.

35. Imfinzi and Imfinzi plus tremelimumab delayed disease progression in Phase III POSEIDON trial for 1stline treatment of Stage IV non-small cell lung cancer. https://www.astrazeneca.com/media-centre/pressreleases/2019/imfinzi-and-imfinzi-plus-tremelimumab-delayed-disease-progression-in-phase-iii-poseidontrial-for-1st-line-treatment-of-stage-iv-non-small-cell-lung-cancer.html. Published March 29, 2020. Accessed March 29, 2020.

36. Reinmuth $\mathrm{N}$, Cho $\mathrm{BC}$, Lee $\mathrm{KH}$, et al. Effect of post-study immunotherapy (IO) on overall survival (OS) outcome in patients with metastatic (m) NSCLC treated with first-line durvalumab (D) vs chemotherapy (CT) in the phase III MYSTIC study. Ann Oncol. 2019;30 Suppl 2:ii77. doi:10.1093/annonc/mdz094.003

37. Cho BC, Reinmuth $\mathrm{N}$, Lee $\mathrm{KH}$, et al. Efficacy and safety of first-line durvalumab (D) \pm tremelimumab (T) vs platinum-based chemotherapy (CT) based on clinical characteristics in patients with metastatic $(\mathrm{m})$ NSCLC: Results from MYSTIC. Ann Oncol. 2019;30 Suppl 2:ii79-ii80. doi:10.1093/annonc/mdz094.002

38. Kaster TS, Yaremko B, Palma DA, Rodrigues GB. Radical-intent hypofractionated radiotherapy for locally advanced non-small-cell lung cancer: a systematic review of the literature. Clin Lung Cancer. 2015;16(2):71-79. doi:10.1016/j.cllc.2014.08.002

39. Roach MC, Bradley JD, Robinson CG. Optimizing radiation dose and fractionation for the definitive treatment of locally advanced non-small cell lung cancer. Journal of Thoracic Disease. 2018;10(21):S2465-S2473-S2473. 
40. Fleming C, Cagney DN, O'Keeffe S, Brennan SM, Armstrong JG, McClean B. Normal tissue considerations and dose-volume constraints in the moderately hypofractionated treatment of non-small cell lung cancer. Radiotherapy and Oncology. 2016;119(3):423-431. doi:10.1016/j.radonc.2016.03.013

41. Maclennan ICM, Kay HEM. Analysis of treatment in childhood leukemia. IV. The critical association between dose fractionation and immunosuppression induced by cranial irradiation. Cancer. 1978;41(1):108-111. doi:10.1002/1097-0142(197801)41:1<108::AID-CNCR2820410116>3.0.CO;2-Z

42. Wild AT, Herman JM, Dholakia AS, et al. Lymphocyte-Sparing Effect of Stereotactic Body Radiation Therapy in Patients With Unresectable Pancreatic Cancer. Int J Radiat Oncol Biol Phys. 2016;94(3):571579. doi:10.1016/j.jijrobp.2015.11.026

43. Crocenzi $T$, Cottam $B$, Newell $P$, et al. A hypofractionated radiation regimen avoids the lymphopenia associated with neoadjuvant chemoradiation therapy of borderline resectable and locally advanced pancreatic adenocarcinoma. Journal for ImmunoTherapy of Cancer. 2016;4(1):45. doi:10.1186/s40425016-0149-6

44. National Comprehensive Cancer Network. nscl.pdf. Non-Small Cell Lung Cancer Version 3.2020. https://www.nccn.org/professionals/physician_gls/pdf/nscl.pdf. Accessed April 6, 2020.

45. Swanick CW, Lin SH, Sutton J, et al. Use of Simultaneous Radiation Boost Achieves High Control Rates in Patients With Non-Small-Cell Lung Cancer Who Are Not Candidates for Surgery or Conventional Chemoradiation. Clinical Lung Cancer. 2015;16(2):156-163. doi:10.1016/j.cllc.2014.10.005

46. Yuan S, Sun X, Li M, et al. A randomized study of involved-field irradiation versus elective nodal irradiation in combination with concurrent chemotherapy for inoperable stage III nonsmall cell lung cancer. Am J Clin Oncol. 2007;30(3):239-244. doi:10.1097/01.coc.0000256691.27796.24

47. Li R, Yu L, Lin S, et al. Involved field radiotherapy (IFRT) versus elective nodal irradiation (ENI) for locally advanced non-small cell lung cancer: a meta-analysis of incidence of elective nodal failure (ENF). Radiation Oncology. 2016;11(1):124. doi:10.1186/s13014-016-0698-3

48. Rosenzweig KE, Sura S, Jackson A, Yorke E. Involved-field radiation therapy for inoperable non smallcell lung cancer. J Clin Oncol. 2007;25(35):5557-5561. doi:10.1200/JCO.2007.13.2191

49. Belani CP, Wang W, Johnson $\mathrm{DH}$, et al. Phase III study of the Eastern Cooperative Oncology Group (ECOG 2597): induction chemotherapy followed by either standard thoracic radiotherapy or hyperfractionated accelerated radiotherapy for patients with unresectable stage IIIA and B non-small-cell lung cancer. J Clin Oncol. 2005;23(16):3760-3767. doi:10.1200/JCO.2005.09.108

50. Vokes EE, Herndon JE, Kelley MJ, et al. Induction chemotherapy followed by chemoradiotherapy compared with chemoradiotherapy alone for regionally advanced unresectable stage III Non-small-cell lung cancer: Cancer and Leukemia Group B. J Clin Oncol. 2007;25(13):1698-1704. doi:10.1200/JCO.2006.07.3569

51. Socinski MA, Blackstock AW, Bogart JA, et al. Randomized phase II trial of induction chemotherapy followed by concurrent chemotherapy and dose-escalated thoracic conformal radiotherapy (74 Gy) in stage III non-small-cell lung cancer: CALGB 30105. J Clin Oncol. 2008;26(15):2457-2463. doi:10.1200/JCO.2007.14.7371

52. Filippi AR, Russi E, Magrini SM, Corvò R. COVID-19 OUTBREAK IN NORTHERN ITALY: FIRST PRACTICAL INDICATIONS FOR RADIOTHERAPY DEPARTMENTS. International Journal of Radiation Oncology ${ }^{\star}$ Biology ${ }^{\star}$ Physics. March 2020. doi:10.1016/j.ijrobp.2020.03.007 
53. Wei W, Zheng D, Lei Y, et al. Radiotherapy Workflow and Protection Procedures During the Coronavirus Disease 2019 (COVID-19) Outbreak: Experience of the Hubei Cancer Hospital in Wuhan, China. Radiotherapy and Oncology. March 2020. doi:10.1016/j.radonc.2020.03.029

54. Simcock R, Thomas TV, Estes C, et al. COVID-19: Global radiation oncology's targeted response for pandemic preparedness. Clinical and Translational Radiation Oncology. 2020;22:55-68. doi:10.1016/j.ctro.2020.03.009

55. Krengli M, Ferrara E, Mastroleo F, Brambilla M, Ricardi U. Running a Radiation Oncology Department at the time of coronavirus: an Italian experience. Advances in Radiation Oncology. March 2020. doi:10.1016/j.adro.2020.03.003

56. Wang D, Hu B, Hu C, et al. Clinical Characteristics of 138 Hospitalized Patients With 2019 Novel Coronavirus-Infected Pneumonia in Wuhan, China. JAMA. 2020;323(11):1061. doi:10.1001/jama.2020.1585

57. Xu Z, Shi L, Wang Y, et al. Pathological findings of COVID-19 associated with acute respiratory distress syndrome. The Lancet Respiratory Medicine. 2020;8(4):420-422. doi:10.1016/S2213-2600(20)30076-X

58. Zhang $\mathrm{H}$, Zhou $\mathrm{P}$, Wei $\mathrm{Y}$, et al. Histopathologic Changes and SARS-CoV-2 Immunostaining in the Lung of a Patient With COVID-19. Ann Intern Med. March 2020. doi:10.7326/M20-0533

59. Gong J, Dong H, Xia SQ, et al. Correlation Analysis Between Disease Severity and Inflammation-Related Parameters in Patients with COVID-19 Pneumonia. Infectious Diseases (except HIVIAIDS); 2020. doi:10.1101/2020.02.25.20025643

60. Burr A, Bayouth J, Bates A, et al. Correlation of Serum Inflammatory Cytokine Levels and Pulmonary Toxicity Following Lung Irradiation. International Journal of Radiation Oncology • Biology • Physics. 2019;105(1):E499. doi:10.1016/j.jrobp.2019.06.1412

61. Tomita M, Ayabe T, Maeda R, Nakamura K. The Prognostic Values of a Novel Preoperative Inflammation-Based Score in Japanese Patients With Non-Small Cell Lung Cancer. World Journal of Oncology. 2019;10(4-5):176-180-180. doi:10.4021/wjon.v10i4-5.1222

62. Yang J-R, Xu J-Y, Chen G-C, et al. Post-diagnostic C-reactive protein and albumin predict survival in Chinese patients with non-small cell lung cancer: a prospective cohort study. Scientific Reports. 2019;9(1):1-9. doi:10.1038/s41598-019-44653-x

63. Xiao X, Wang S, Long G. C-reactive protein is a significant predictor of improved survival in patients with advanced non-small cell lung cancer. Medicine. 2019;98(26):e16238. doi:10.1097/MD.0000000000016238

64. Wang XS, Shi Q, Williams LA, et al. Inflammatory cytokines are associated with the development of symptom burden in patients with NSCLC undergoing concurrent chemoradiation therapy. Brain, Behavior, and Immunity. 2010;24(6):968-974. doi:10.1016/j.bbi.2010.03.009

65. Gray JE, Villegas A, Daniel D, et al. Three-Year Overall Survival with Durvalumab after Chemoradiotherapy in Stage III NSCLC_Update from PACIFIC. Journal of Thoracic Oncology. 2020;15(2):288-293. doi:10.1016/j.jtho.2019.10.002

66. Fang $\mathrm{P}$, Swanick CW, Pezzi TA, et al. Outcomes and toxicity following high-dose radiation therapy in 15 fractions for non-small cell lung cancer. Pract Radiat Oncol. 2017;7(6):433-441. doi:10.1016/j.prro.2017.03.005 
67. Westover KD, Loo BW, Gerber DE, et al. Precision Hypofractionated Radiation Therapy in Poor Performing Patients With Non-Small Cell Lung Cancer: Phase 1 Dose Escalation Trial. Int J Radiat Oncol Biol Phys. 2015;93(1):72-81. doi:10.1016/j.ijrobp.2015.05.004

68. Iyengar P, Westover KD, Court LE, et al. A Phase III Randomized Study of Image Guided Conventional (60 Gy/30 fx) Versus Accelerated, Hypofractionated (60 Gy/15 fx) Radiation for Poor Performance Status Stage II and III NSCLC Patients-An Interim Analysis. International Journal of Radiation OncologyBiology*Physics. 2016;96(2, Supplement):E451. doi:10.1016/j.ijrobp.2016.06.1763

69. Robinson CG, Contreras J, DeWees TA, et al. Phase I Study of Accelerated Hypofractionated Proton Therapy and Chemotherapy for Locally Advanced Non-Small Cell Lung Cancer (LA-NSCLC). International Journal of Radiation Oncology • Biology • Physics. 2018;102(3):S17. doi:10.1016/j.ijrobp.2018.06.132

70. Agolli L, Valeriani M, Bracci S, et al. Hypofractionated Image-guided Radiation Therapy (3Gy/fraction) in Patients Affected by Inoperable Advanced-stage Non-small Cell Lung Cancer After Long-term Follow-up. Anticancer Res. 2015;35(10):5693-5700.

71. Osti MF, Agolli L, Valeriani M, et al. Image Guided Hypofractionated 3-Dimensional Radiation Therapy in Patients With Inoperable Advanced Stage Non-Small Cell Lung Cancer. International Journal of Radiation Oncology ${ }^{\star}$ Biology ${ }^{*}$ Physics. 2013;85(3):e157-e163. doi:10.1016/j.jirobp.2012.10.012

72. Maguire J, Khan I, McMenemin R, et al. SOCCAR: A randomised phase II trial comparing sequential versus concurrent chemotherapy and radical hypofractionated radiotherapy in patients with inoperable stage III Non-Small Cell Lung Cancer and good performance status. Eur J Cancer. 2014;50(17):29392949. doi:10.1016/j.ejca.2014.07.009

73. Din OS, Harden SV, Hudson E, et al. Accelerated hypo-fractionated radiotherapy for non small cell lung cancer: results from 4 UK centres. Radiother Oncol. 2013;109(1):8-12. doi:10.1016/j.radonc.2013.07.014

74. Kelly V, Maguire J. 134 Long term local tumour control in inoperable NSCLC treated with accelerated hypofractionated radiotherapy and concurrent cisplatinum and vinorelbine. Lung Cancer. 2016;91:S49. doi:10.1016/S0169-5002(16)30151-9 